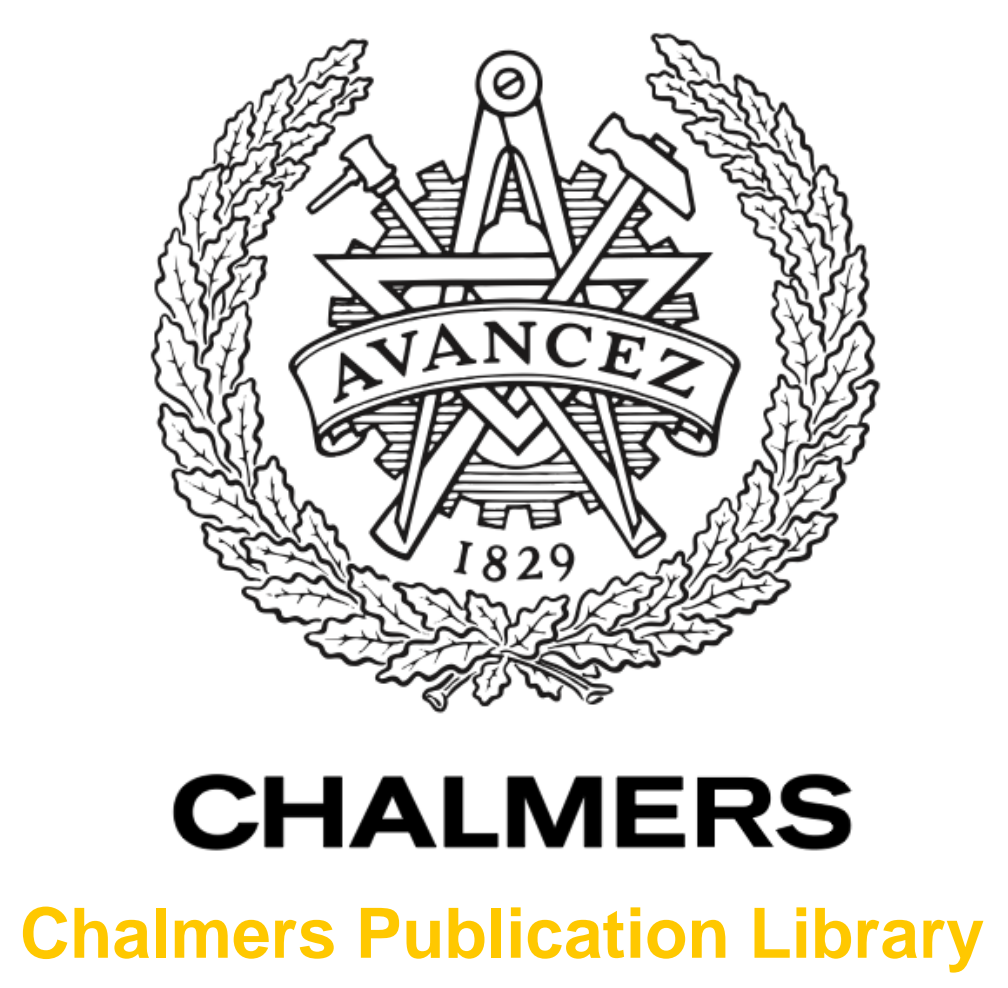

\title{
'Taking off my glasses in order to see': exploring practice on a building site using self-reflexive ethnography
}

This document has been downloaded from Chalmers Publication Library (CPL). It is the author's version of a work that was accepted for publication in:

\section{Construction Management and Economics (ISSN: 0144-6193)}

\section{Citation for the published paper:}

Löwstedt, M. (2015) "'Taking off my glasses in order to see': exploring practice on a building site using self-reflexive ethnography". Construction Management and Economics, vol. 33(5-6), pp. 404-414.

http://dx.doi.org/10.1080/01446193.2015.1066021

Downloaded from: http://publications.lib.chalmers.se/publication/222869

Notice: Changes introduced as a result of publishing processes such as copy-editing and formatting may not be reflected in this document. For a definitive version of this work, please refer to the published source. Please note that access to the published version might require a subscription. 
To cite this paper: Löwstedt, M. (2015) 'Taking off my glasses in order to see': Exploring practice on a building site using self-reflexive ethnography.

Construction Management and Economics, 33(5-6), 404-414.

\title{
'Taking off my glasses in order to see': Exploring practice on a building site using self-reflexive ethnography.
}

\begin{abstract}
There has recently been a growing interest for ethnographic studies in construction, predicated upon the belief that ethnographic research in the construction industry can provide a powerful way of illuminating construction practices in new ways. Focusing on the ethnographic method, it is demonstrated how a self-reflexive ethnography can contribute to a deeper understanding of the variations, contradictions and tensions underlying practices on a building site, thereby serving as a complement to other qualitative approaches. A short four-week ethnographic study illustrates how the subjective "I" of the ethnographer can be used as an active producer of knowledge, by reflecting on how insights from an individual's role, both as an observer and as a worker, can account for the complex interplay between socialities and materialities on a building site. The results also contribute to the discussion regarding the length of ethnographic studies, by showing how valuable insights can be drawn from shorter "ethnographic episodes", studied through a self-reflexive lens.
\end{abstract}

Keywords: Building site, construction practice, ethnography, self-reflexivity, 


\section{INTRODUCTION}

Building sites have been described as chaotic, complex and in constant flux (e.g. Cicmil and Marhall 2005; Ness 2010), constituting "ad hoc environments" that undergo rapid temporal and spatial changes; they are therefore often prone to unpredictable configurations (e.g. Bresnen 1990; Groák, 1994). It has been argued that those workers engaged in this kind of reality rely heavily on practice-based learning between individuals and groups rather than learning from technical and managerial systems (e.g. Styhre et al. 2004; Knauseder 2007). The nature of learning and practices on site, therefore, often reside in a situated body of construction knowing, mobilized mainly in practices on a site. These can only be known by being in place, amidst the actual activities as they unfold (Pink et al. 2010).

It has been argued that an ethnographic approach is particularly beneficial to study the particular socio-material conditions of building sites (Pink et al. 2010). It may enable problems to be reframed in ways which can highlight both the specificities of the context to which they are related and the socio-material experiences through which they unfold (Dainty 2008; Pink et al. 2012) in ways that are not accessible through traditional methods such as standard, focus groups or mere observations (Tutt et al 2012). While ethnographic studies of the "lived" realities of building sites have traditionally been scarce, an increasing numbers of researchers are adopting the approach to generate new insights in regard to a number of areas, such as: tacit knowledge and associated skills (Strati 2003), situated learning and safety practices (Gherardi and Nicolini 2002), 
communication practices of migrant workers (Tutt et al. 2012), to name a few (for further examples, see Pink et al. 2012).

However, alongside these advances is an ongoing discussion concerning the challenges relating to the application of an ethnographic approach to studies of building sites. “Traditional” ethnographic approaches, often associated with anthropological research, involve a researcher becoming thoroughly immersed in the activities of a certain field for an extended period (in terms of years) of time (e.g. Fine 2003; Atkinson et al 2007). The extent of such an approach has been highlighted as a general challenge for its use in construction research, making it unpractical and daunting for the majority of researchers, who are after all not grounded in an ethnography tradition (Pink et al 2012). However, the use of the method has also been problematized in regard to the specific characteristics of building site practices. For example, Marshall and Bresnen (2012: 109) argue that while lengthy engagement might be appropriate for fields where the social practices unfold in a relatively bounded time and space, it becomes problematic in regard to building sites where the activities and actors are spatially distributed and follow complex interlocking temporal patterns that shift their "centre of gravity" over time (see also Thiel 2012). By using the term "relatively", Marshall and Bresnen acknowledge that social practices never are bounded in time or in space, regardless of field, but that building sites environments distinguish themselves in these regards.

This means that the particular characteristics of building sites that would encourage a researcher to be amidst the practices as they unfold are the same particular characteristics that make lengthy ethnographic studies challenging in this context. There 
have therefore been recent calls to explore new innovative ways of using the ethnographic method, both in order to make it more accessible in general, but also to find ways that are better suited for the shifting temporal and spatial patterns that characterize building sites (Pink et al 2012).

The purpose of this paper is to contribute to this discussion by exploring the insights that can be constructed from a shorter ethnographic study. I use "construct" to denote a difference in approach from more traditional ethnographic studies, where the objective is usually to discover intrinsic "invisible" logics of building-site practices (e.g. Applebaum 1999; Moore 2012). In this paper I draw instead on a self-reflexive approach to explore how a more explicit engagement with the subjective researcher (myself) can help provide for new perspectives of the complex practices of a building site. Based on a relatively short field study (four weeks) on a building site, I turn my attention inwards and reflect on how my selves as researcher observer and dogs-body worker added up to a new "whole" in regard to the unfolding interplay between socialities and materialities, in which I am the active producer of knowledge (rather than the discoverer).

Thus I contribute to the ongoing discussion regarding ethnographic approaches in construction research by showing how valuable insights through enhanced critical awareness of my own pre-conceptions, emotions and behaviours can be drawn from shorter "ethnographic episodes". While the type of knowledge that can be generated from this approach differs from that of longer ethnographies, I argue that it can be used as an invaluable complementary method in order to generate new perspectives of the practices of building sites. 


\section{ETHNOGRAPHY AND (SELF)-REFLEXIVITY}

Brewer (2000:10) described ethnography as "the study of people in naturally occurring settings or fields". The objectives are to understand the social meanings and activities of the people in a given "field", in order to be able to tell the "inside story"; the approach, thus, involves close engagement and often participation in the activities of the field being studied (ibid). While there seems to be scant instruction as to how long an ethnographic study needs to be (Gherardi and Niccolini 2002), "traditional" approaches, often associated with anthropological research, would recommend extended periods (several years) for the research to yield in-depth insights into the beliefs, practices and behaviours of the people inhabiting the field (Fine 2003; Atkinson et al 2007). As for all research these insights also have to be reported back to others (Rosen 1991) in order to enhance conceptual understanding and contribute to building and extending theory (Fine 2003).

Ethnographic studies have been widely discussed in various social-science research communities, and much attention has been directed towards the intrinsic tensions and contradictions that are embedded in the ethnographic objective and approach. Gherardi and Nicolini (2002: 199), quoting Geertz (1973: 29), argue that all ethnography is in fact "quasi-ethnography", meaning that we should accept that an ethnography is "essentially contestable" and "intrinsically incomplete" One of the reasons why it would be vain to think that 
anyone could live up to the expectation of a "complete ethnography" is that it is impossible to step completely outside one's own research experience to adopt a "professionalized distance”, as advocated by e.g. Silverman (1972: 189).

Bourdieu acknowledged and discussed this concern, arguing that there are mainly three types of biases that would blur the "sociological gaze" of an ethnographer entering a certain field (Bourdieu and Wacquant 1992: 39-40). The first bias is the biological and social origins (class, gender, ethnicity, etc.) of the individual researcher. This is the most obvious bias, and therefore maybe the more readily controllable one by means of self-reflection and self-criticism, for example. The second bias is less often discerned; it is linked to the position that the analyst occupies, not in the broader social structure, but in the microcosm of the academic field, that is, in the objective space of possible intellectual positions offered to him or her at a given moment and in a given situation. Researchers always owe a debt to their situation (could also be seen as status) in the academic field they inhabit, in which they define themselves (and are defined) in relational terms to other academics. The third bias Bourdieu calls the "intellectual bias", which denotes the gap between practical logic and theoretical logic. Researchers have a tendency to "view the world as a spectacle to be interpreted rather than as concrete problems to be solved practically" (ibid. 39).

In regard to the third bias Bourdieu (1990) argued that there is a sort of incompatibility between our scholarly thinking and this strange thing that is "practice", and warned that whenever we fail to critique the presuppositions inscribed in the fact of thinking the world, of retiring from the world and from 
action in the world in order to think that action ..." (Bourdieu 1990:382), then we risk collapsing practical logic into theoretical logic (Bourdieu and Waquant 1992:40). Thus, when a researcher enters a community of practice or a "field", the researcher's understanding of that practice will both be restricted to and biased by his or her existing intellectual dispositions or in Bourdieu's term his or her "habitus". Czarniawska (2007:21) suggested that "an observer can never know better than an actor; a stranger cannot say more about any culture than a native, but observers and strangers can see different things than actors and natives can". In line with these arguments it would seem very challenging for a researcher to first be able to disregard his or her theoretical preconceptions in order to be able to discover the "inside story" of a field (Brewer, 2002), and also then be able to re-tell that story to others in and on theoretical terms (Fine 2003).

Since the turn to reflexivity in ethnographic methods (Clifford and Marcus 1986) was promoted, it has been widely accepted that ethnography is indeed inherently a reflexive and subjective research approach. Applying or superimposing a reflexive lens on ethnography is to accept and embrace that the ethnographic experience is something that is intrinsically personal (Cunliffe 2010; Van Maanen 2011), and to acknowledge that "who" the ethnographer is influences "what" is said and "how" concerning the ethnographer's subjects of study (Jarzabkowski et al. 2014).

Sage (2012) pointed out that the subjective "I" of the researcher remains absent in construction research accounts and books, and that there is a lack of self- 
reflexivity in much of the ethnographic studies in construction. Even though reflexivity can be seen as being intrinsically embedded in the "self" (e.g. Gouldner 1970), Sage (2012) used the term "self-reflexivity" to denote an explicit focus on the part of the researcher on his or her self in the research. By keeping attuned to his own transforming identity when doing his study on a building site, Sage illustrated how he would alternate between different roles on the site (ethnographer-as-interloper, ethnographer-as-spy, ethnographer-as-consultant). By taking a self-reflexive stance in regard to that transformation, he developed a more profound understanding of the research-practice relationships in construction.

There are other examples of more "traditional" ethnographic studies of building sites in which the subjective "I" indeed is present (e.g. Appleabaum 1999 and Moore 2012), but Sage's use of self-reflexivity distinguishes itself from these other studies in terms of using reflexivity in order to construct new perspectives for himself rather than discovering the perspectives of others (cf. Alvesson et al 2008). That is, Applebaum's (1999) and Moore's (2012) engagement in buildingsite practices was to facilitate discoveries of "invisible" logics and thereby enable them to foreground the participants' (subjects') voices; Sage (2012), on the other hand, used a self-reflexive approach to allow space for the subjectivity of the researcher to be an active producer in the pursuit of new perspectives and new awareness of the intertwined roles of researcher and researched in the construction of new knowledge. 
Pink et al (2012) argue that ethnography is a methodology that develops mainly in practice and is perhaps therefore best defined through a consideration of how it is practised. In this paper I explore how a self-reflexive approach can be used to construct new valuable insights relating to the complex practices of a building site, using experiences drawn from merely a shorter ethnographic study. While the distinction between "constructing" something and "discovering" something could be seen as being embedded in much broader epistemological and ontological debates, it also serves well here to denote a more practical distinction in terms of ethnographic approach.

\section{THE STUDY}

The study draws on data from a four-week long field study at a building site in January 2014. The subjective "I" in this account is me, Martin Löwstedt, the ethnographer and the author. I want to start by disclosing some aspects that shape my "sociological gaze" (Bourdieu and Waquant 1992). I am a 32-year-old male. I had been a PhD-student for four years at the time of the study and was at the end of finishing off my doctoral thesis. My educational background before starting my PhD was not in construction. My B.Sc. was in Industrial Economics and Management and my M.Sc. in Management and Economics of Innovation. My supervisor told me that one of the reasons I was hired for the position was because I had a different background than construction and engineering - she wanted a PhD-student devoid of construction baggage, someone who had not been cast in a construction mould. The original purpose of the $\mathrm{PhD}$ project was 
to study corporate strategy in a large construction company, taking a longitudinal approach. This original plan developed into studies of organizational change, observations of strategy workshops, and then lately an ethnographic study of a building site.

Bourdieu argued that a researcher's "microcosm of the academic field" is the "objective space of possible intellectual positions offered to [the researcher] at a given moment" (Bourdieu and Wacquant 1992: 39). Throughout my four years as a PhD student I had mainly used narrative theories and analysis (Löwstedt and Räisänen 2012), a Strategy-as-Practice perspective (Löwstedt 2015), and social identity theories (Löwstedt and Räisänen 2014) in order to examine and understand phenomena in the construction industry. Not ever having been on a building site I must admit that I had my own preconceptions, largely influenced by my own research and my reading, regarding what it would be like and what I was going to find. I expected (to name a few things), the building site to be chaotic (e.g. Cicmil and Marhall 2005), unpredictable (e.g. Groák, 1994), relatively disorganized, adhering to a culture of ad-hoc problem-solving (e.g. Styhre et al. 2004; Knauseder 2007; Löwstedt and Räisänen 2012; Löwstedt and Räisänen 2014). I expected the social environment to be rough and machooriented (e.g. Applebaum 1999; Dainty et al. 2000; Greed 2000; Hayes 2002; Ness 2012). While ethnographic studies generally are not seeking to test any prior hypothesis (Dent 1991) these examples could be seen as my preconceptions that might affect my sociological gaze in regard to the field of practice (cf. Bourdieu and Waquant 1992). 


\section{THE SETTINGS}

The purpose of the field study was to complement previous studies that I had carried out throughout my research project. Doing an ethnographic study of a building site was a complement in terms of both context studied and method used. To gain acceptance for my research and admission to a site, I said that I wanted to learn more about how things work in practice on an actual building site. I had already gained the confidence of many managers at various levels in the organization, having carried out a large number of interviews and observation studies in order to explore various aspects of practice in a large construction company (here referred to as Alpha). To obtain a more complete picture of the practices of Alpha I felt a field study on a building site was necessary and I wanted to hear workers talk, and rather than interviewing them I thought working with them would be a natural way of eliciting information. For practical reasons I did only have four weeks to spend, but as a complementary study I figured that this time would suffice.

The construction site project I entered was operated by Alpha, and comprised the construction of 40 residential apartments in two buildings. I got access to the site via a professor at my department who knew a regional manager who, in turn, directed me via a district manager to the site manager at the particular site. A few days before my first day, I visited the site to meet the site manager, expecting that he would want information about me, my research and my intentions and goals for the four weeks. I was a bit concerned about this because I did not have a well-thought out agenda for my field study beyond acquiring experience of working on site with other workers. I imagined that such a simple 
ambition would maybe not suffice for the site manager, so I prepared a number of items that I could expand on if he asked. However, our meeting was very short. He just gave me some brief information about the site and sorted out some minor practicalities such as giving me an access card, and then welcomed me back the following Monday to start. Before I left I asked him if there was anything in particular I should remember or think about before starting on Monday. His answer was: "Yeah, don't be late"

\section{ON-SITE EXPERIENCES}

I started work on the site on the second Monday of January 2014. By this time the project was about $70-80 \%$ into its projected progression. I remember my first day very well. The workday started at 6.30 a.m. and I had quite a long journey by bus to get to the site. Being worried about oversleeping I had double alarm clocks ringing at 5.15 that morning. When I arrived, on time, at the site one of the team leaders gave me a short mandatory safety introduction and my work kit, and that was it. No one really paid attention to my being there; everyone just went to work as usual and I was left sitting alone inside the barrack feeling rather uncomfortable with the whole situation. However, my strategy for the field study was not just to stay incognito and observe, but to actively participate in the day-to-day activities as much as possible. I regarded this as an eligible strategy for many reasons. One reason was that this seemed to be the best way to study the setting in such a way that meaning was not imposed on it from outside (Brewer, 2000), i.e. rather than my presence being associated with 
someone that observed, I wanted to try to blend in by working like everyone else. As it turned out, this strategy proved to work even better than I could ever have expected.

The work kit I was given that first day was the same as everyone else on site was wearing. The safety helmets that we wore on site followed colour-coding that showed the rank of the wearer. I learned that the site manager and the site leaders wore white helmets, the construction workers' were blue and the apprentices and visitors had red helmets. Mine was red, which turned out to be a great advantage if one wanted to blend in. There were about 15-20 apprentices on site, and a large number came and went from week to week. I realized that many faces were new to many people, and not everyone knew everyone's name, so all in all it seemed as if I passed rather unnoticed. Another reason for my strategy to actively participate in the construction work was that I imagined that my understanding of the practices on site would be more profound if I learned by doing. This ambition was amply satisfied since by the end of the second day I had my fair share of chores.

Initially my tasks mainly consisted of carrying and moving various material and tools as well as a lot of cleaning and clearing up. This could consist of moving large piles of building timber from one place to another ( $\approx$ four hours), throwing plasterboards away for disposal ( $\approx$ one and a half hours), carrying parquet between different floors in the building ( $\approx$ two hours), or cleaning the building trash out of apartments ( $\approx$ one day). I learned from the site manager that it was common for apprentices to get these more "boring" tasks at the beginning. The 
construction workers interpreted my red helmet as signaling "apprentice"; I

could hardly go anywhere on site before some construction worker asked me to do some tasks. However, in due course I was assigned to do "real" construction work as well. Even though I did not have any construction training at all, I accepted all the tasks that were assigned to me, which turned out well. Before the end of my field study, I had performed most of the tasks that a regular construction worker does on a building site, for example measuring, sawing and putting up beams in an outdoor storage room, putting up plasterboards, putting up boards using a nail gun, doing range measurements with a laser, placing clinkers, receiving deliveries, and directing a crane operator.

\section{VARYING ROLES AND TRANSFORMING PERSPECTIVES}

There were several motivating factors to focus on the tasks assigned and to perform my utmost. First, I did not want to make any mistakes that could draw attention my way. Second, I wanted them to recognize that they could trust me with the tasks they gave me in order for them to give me more without having to think twice about it. I also realize that a significant motivational factor for me to be so focused on the work assigned me was grounded in myself - in my selfhood. I am a very competitive person; I want to perform well regardless of what I do, and furthermore I found that I really enjoyed doing physical work during these weeks. This really made me focus on the tasks, fully engaging in order to fulfill each one of them perfectly. 
All these circumstances continuously transformed both my role and my perspective on site. After only a few couple of days at the site I was so overwhelmed with construction work that I had no time to take field notes and no time for reflection. I felt as if my worker role occasionally grew out of proportion and I also realized that although carrying piles of lumber all on my own for four hours running made me useful on site, it hardly provided me with much useful data concerning the practices on site. In the course of these four weeks on site I was constantly pulled into the worker role, which I actively had to step out of in order to be able to observe. For me this constant fluctuation between my observer role and my worker role became rather problematic, and while being at the site I thought of this constant flux merely as an unfortunate event that impinged on the grand purpose of the study.

It was only a few months after being on site, when I was reflecting and writing about the experience, that I realized that the fluctuating roles and perspectives in fact were a true resource. In the following section I present field note extracts that describe the varying roles and changing perspectives. The field notes are sorted into "ethnographic episodes" based on two different aspects of on-site practices: planning and safety, but more importantly, they are sorted to represent an observer perspective and a worker perspective on these two phenomena. In a concluding discussion I argue that these two perspectives complement each other and provide a deeper account of complex tensions obtaining in various practices on a building site. 


\section{ETHNOGRAPHIC EPISODES: BEING OBSERVER, BEING WORKER}

\section{Practice: Planning on site}

\section{Observer Perspective}

My overall impression from observing the practices on the building site was that there was a lack of systematized control and planning. Even where there was planning, it seemed as though no one paid too much attention to it. The practices on the site rather seemed to be characterized by ongoing reactive and personbased problem solving.

A typical episode could be:

Two construction workers come to talk to the site team leader about how to construct a stair. The team leader starts to explain to them. At first they don't understand him, but soon they catch on. One of the workers says to the team leader: "You just thought of this now didn't you" and the team leader seems delighted and smiles "Hell, yeah". This intrigued me and when the workers left I asked the team leader if there really was no construction plan for the stair. The team leader said: "No, no, no". Another team leader overheard this and says "Come on, of course there is a construction plan for the stairs" Team leader 1 replied: "No there isn't" Team leader 2 said:" I know for a fact that there is" Team leader 1 then said:" Ok there might be one...but you know that there is a reality also, right?"

This made quite an impression on me, and the next day I asked the team leader: "how the building process progressed and if everything went according to plan" 
Team leader: "I really don't know" Me: "Don't you have any plan?" Team Leader: "No...I mean I don't feel like I should have to sit and plan...I made one plan in the beginning, but I think that was flawed already the very first day ... and then I didn't feel like sitting down and making yet another one."

This approach towards plans and planning was not only a characteristic of this particular team leader, but also typical for all the construction workers on site. The behaviour included planning of the building process as well as the specific building plans. In general they seemed very sceptical towards the building plans and towards the architects that designed them: "they don't know about reality", "they can't be trusted", "there is almost always something wrong". A common practice for the workers on site was to superimpose their own solutions on the plans and "just solve" whatever issues arose. They usually communicated their solutions to the team leaders after solving them: "The plan said that ...but that was no good because...so we did this instead..."

I have no construction background myself, so I could not discern whether the plans were flawed in the first place or not. I did observe scepticism and indifference towards the official plans; not only did the site workers assume that the plans were wrong, but I could also sense that they wanted the plans to be wrong so that they would have an excuse to apply their person-based problem solving. The reason for this behaviour seemed to be a collective pride related to on site craftsmanship and the trait of being a good "problem solver" and my inference when observing this was that the attitude towards plans and planning was a socially embedded phenomenon. 


\section{Worker perspective}

As I progressively transformed into the worker role through my active participation in the construction process, I also progressively started to think of plans and planning in a different way to what my academic framing had taught me. After working on the site for a while I could sympathize with my co-workers' skepticism and reluctance towards plans. I realized that no plan could in detail account for the high degree of unpredictability embedded in the building process; the complex chains of dependencies and variations between social interactions, materiality, and the unpredictable physical environment, and so on.

The following is a very typical on-site episode:

One of the team leaders assigned me the task of receiving a shipment of marble window frames. My task was to be at the delivery location, to review the shipment, sign it off, and then pile up the frames outside the building. However, when I arrived at the location it starts to rain. The delivery guy informs me that it is not good for the frames to lie out in the rain. Since the frames are very heavy and the space very limited inside the building, I do not want to risk carrying them to any inconvenient location. So I decide to go and find the team leader to ask him where I should put them.

I look for him for about 20 minutes and finally I find him in the second building on the fourth floor. He tells me: "I don't know... You have to put them wherever there is room". I go back to the first building and look for a place on the first floor, but the flooring isn't completed in these apartments. I ask the worker there when he will do the flooring in order to ascertain whether I can stack the frames there or not. He tells me that he does not know; he needs to wait for the filling to be done first, and he does not know when that will 
be, but that it should be sometime in the afternoon. So I go to the second floor. It is kind of chaotic there because a shipment of doors has just arrived and someone has just stacked these in the stairwell so there is no room for me to access any of the apartments on that floor. I go to the third floor. There the flooring is completed in one of the apartments so I decide to put the window frames there. I go down and start to carry them up. When I am about half way through with the task, one of the workers stops me and asks me if I could carry the frames to the fourth and fifth floors instead. He tells me that he is the one that is supposed to put them in place and asks me if I can carry them directly to the rooms where they are supposed to be put in place. I say yes, no problem. However when I arrive on the fourth floor carrying one of the heavy frames I see that there are cabinets standing everywhere and blocking the space. The floor dresser of that floor had moved them there because he needed room in the kitchen where he was putting in floors. So I had to carry the frame back down again, and put it right back where it had been. I then tried to find the worker to inform him that there was no room for the frames where he wanted them, but I couldn't find him. Then I tried to find the team leader to inform him where I had put the frames in the end, but I couldn't find him either. And then I forgot to tell him when I saw him, but he never asked.....

This episode is very typical of the practices I witnessed and experienced on the site. It illustrates the constant negotiation of on-site space and time and the effect the physical environment can have on the sequences of events; here, for example, it suddenly starts to rain. It also illustrates how complex and juxtaposed all the micro processes are, and how hard they are to anticipate. The team leader did not know where to put the frames; and he didn't know where I actually put them in the end; he also did not know that one of the workers needed them on the fourth floor; and that that worker, in turn, did not know that 
there were cabinets standing where he wanted the frames to be. He also didn't know where I put them in the end, and he could only start installing them after he finds them, and after the floor dresser is done with the floor - and so on. From a worker perspective, the unpredictability of the building process on site seemed to spring from the aggregate of a myriad of episodes like this.

\section{Practice: Safety on site}

\section{Observer perspective}

On my very first day on the site I was given a safety introduction by one of the team leaders. This introduction was mandatory and was given to everyone that was going to spend time on the site, including all the subcontractors and visitors. The introduction took about 10 minutes and included pretty much what I expected from a safety introduction, i.e., there were no surprises; there was no more than the bare minimum. One thing that was stated in the safety introduction was that it was absolutely mandatory for everyone on site to wear all the safety equipment at all times, including helmet, glasses, jacket, shoes, and gloves. This was also stated on signs that were put up on the fence that surrounded the building-site area and on the doors of the barracks. Yet observing the workers on site, I noticed how this regulation was broken time and time again. The helmets were on the majority of times, but the jackets, gloves and glasses were taken off countless times. On one occasion I asked the team leaders about this, and they seemed to have rather different opinions on the matter; one expressing indifference, the other frustration: 
Team Leader 1: "We have more important things to think about"

Team Leader 2: "Yeah, but if you didn't have to nag about it all the time like some kindergarten teacher... then you would have time for more important things"

At this point I could see that the safety regulations were not followed, but I was not sure about the reasons, and even when I asked I could not get consistent answers. I heard reasons like "forgetting”, "not important”, “yeah, yeah...I know”. My initial inference was that this was related to, and embedded in, the macho culture that I observed on the site. However, when experienced from a worker's perspective, I saw it also in a different way.

\section{Worker perspective}

EXTRACT 1: On one of my first days on site I was asked to move large piles of parquet floors boards from one floor to another. They were quite heavy, and it did not take long for me to start sweating a lot. In addition to the heavy workload and the warm safety jacket, there were also hot fans operating in the apartments and in the stairwell. The buildings were built out of concrete and these fans were placed there to dry out the concrete, which needed to be done as fast as possible because other building sequences depended on it. However, all of this made it incredibly hot and I had to take my jacket off. Simultaneously mist started to form inside my safety glasses, and I therefore had to take them off as well - in order to see. I kept doing this when I needed to and I learned that everyone did this and that it was an accepted behaviour. 
Another example exemplifying the tensions concerning safety on the site is taken from my first week when I was helping the construction workers with various tasks:

EXTRACT 2: One of the construction workers approached me and asked me if I could help one of them out putting up safety fences on one of the rooftops. I met the worker and he didn't say much, just "lets go then", and I followed him. We accessed the rooftop by climbing the building scaffolding. Once we were up, I started to feel a bit uncomfortable. (I want to state here that I am not afraid of heights and see myself as something of a daredevil). But this situation was actually making me a bit scared. We were about 20-30 metres up; there were pretty strong winds, and I could feel them grabbing me when we moved around. The rooftop was a classic pitched roof with two verges ending with edges. Our task was to put up extra safety fences at these edges, and in order to do so we needed to stand on ice-layered snow and lean out on the edge. There were some safety fences up in place; however there was a metre-long gap between them and the edge that we easily could fall through. Moreover, the poor condition of the fences was the reason we were sent up to put up new ones. If I had been in that situation with one of my friends or colleagues from university I would definitely have pulled out, but now I stayed. I remember that I kept saying to myself: "this is just great, getting killed doing a field study".

What I also learned during these weeks is that it can be painful being a construction worker. Doing work in such a chaotic environment, with material lying around everywhere made it unavoidable not to get hurt. During these weeks I tripped on an electric cable on the floor and fell onto a metal bar hurting my elbow; I walked into an electric cabinet and hurt my knee; I somehow managed to stick my thumb into a hole in a wall and twist it; a large wooden 
beam hit my arm when sitting and measuring leaving me with a large bruise, which could easily have been much worse because it fell towards my neck and one of the workers screamed at me enabling me just barely to get my arm up in time to protect my neck. Now in retrospect it actually appears rather unwise, from a safety perspective, to participate in the activities of a building site without any prior experience or formal training. However, there is no denying that I learned a great deal from it. By experiencing these events from a worker perspective it became very clear to me that just following established safety guidelines is not always enough to avoid incidents on the site.

\section{DISCUSSION}

These episodes describe how my own perspectives transformed and fluctuated between being foremost an observer and being foremost a worker while doing an ethnographic study on a building site. The observer perspective and the worker perspective presented in the former section are simplifications; in reality they are approximations and overlapping. However, they serve to demonstrate how a self-reflexive ethnographic approach enabled me to move between my own preconceptions and the situated lived realities of a building site.

The team leaders and the workers discussed the practice of planning in terms of "time-wasting" activity and expressed a lack of trust in what a plan could "know about the real reality on a building site". This could, from an observer perspective, be interpreted as relating to the rather chaotic environment on the 
site (a causal relation), and would also support one of the preconceptions I had before entering the site regarding an underlying socially embedded aversion towards formalized planning practices (e.g. Styhre et al 2004; Knauseder 2007; Löwstedt and Räisänen 2012; Löwstedt and Räisänen 2014).

However, by working on site myself and experiencing the constant negotiation of time and space (e.g. Bresnen 1990; Groák, 1994), embedded not only in the social aspects on the site, but also in the physical and the material, I gradually started to understand the dissonances between the formal linear plans (Christiansen, 2012) and their more circular enactments in reality. These enactments often called for improvisations which would be impossible to incorporate in the formal documents. Thus, from a worker perspective, the scepticism towards formal plans seemed to be the consequence of rather than the cause of the specific physical and material conditions on the building site, conditions which were beyond the control of the managers (e.g. bad weather) and which could catalyse complex knock-on effects, which propagate through temporal space and time as series of unpredictable and "unplanable" contingencies.

By the same token, from observing the workers on site I discerned as well as experienced resistance to the use of the safety work kit and to the overall precautions, which resonated with my own preconceptions and the often discussed social factors of a macho culture on building sites (e.g. Dingsdag et al. 2008; Ridley and Channing 2008). I found myself behaving in the same macho way when climbing the rooftop to install safety fences even though it felt very 
unsafe to do so. It is hard to pinpoint or characterize the explicit dimensions of the social climate that pressured me to do it, other than an underlying (but strong) feeling that I would have received negative attention had I refused to do so because it didn't feel safe.

However, when I started to transform from being foremost an observer into being foremost a worker other insights regarding the safety practices on site emerged as well. During the four weeks on the site I also took off my safety work kit on several occasions, for other reasons than to conform with the workers on site. The reference "taking off my glasses in order to see" in the title of this papers has both a figurative and a literary meaning. By taking my "observer glasses off" and taking on a self-reflexive mode I realised that I took off my safety glasses because of the specific physical and material circumstances on the site. Temporally absorbed by my task as a worker, I remember thinking to myself that if "they" want "us" to wear the safety equipment then why don't they give "us" some less warm alternatives to wear for the unbearably hot conditions we have to endure (i.e. for the temporal episode when hot fans needed to run in order to dry out the concrete as fast as possible. However when these fans were turned off, it was really cold instead because of the (temporal) winter season, and the warm work kit was then needed). Also, by constantly hurting myself while in the worker role, I could also see that the issue of safety hazards on building sites is both a matter of a particular social climate, as well as embedded in the unpredictable physical and materiality-based circumstances. 
These realizations show how the two different perspectives generate different insights which are nevertheless complementary and synergistic. The point is not to give priority to any perspective, but to highlight how an engagement with the different perspectives enabled me to construct a new perspective of the complex socio-material practices of a building site. What I mean by a "new perspective" is the emerging insight regarding the multiplicity in itself. While on the site I did think about the tension between the worker role and the observer role merely as an unfortunate circumstance and a method-related challenge in need of attention. It was only some months after the experience, while trying to write about it, that I realized that this tension was in fact a valuable perspective in its own right.

This goes to show how a self-reflexive stance is a focal point of my findings, as this new perspective was constructed through engagement with my subjective "I", not only in the observing, the working, and the writing, but also in the overlapping and interrelated living (cf. Gouldner 1970: 489). Self-reflexivity in regard to my own "provisional living" in the site context can be seen as something that runs through the whole experience - being me, as a researcher, going out trying to be an observer, and then being a worker in order to try to understand practice in a field, but also being me working as myself, and writing as myself - that let me to challenge and construct a new space in my own microcosm of the academic field (Bourdieu and Wacquant 1992).

\section{CONCLUSIONS AND IMPLICATIONS}


Even though there exist few guidelines on how long an ethnographic study needs to be (Gherardi and Nicolini 2002), my four weeks spent on a building site would most likely be considered a particularly short ethnography within the field of “traditional" ethnographic practices (e.g. Fine 2003; Atkinson et al 2007). While it is less about the time per se, and more about the depth of engagement achieved, the amount of time spent in a certain field still corresponds with the type of knowledge that can be obtained. This applies also to my study. While longer ethnographic studies (one or two years) have the potential to discover the "inside story" (Brewer 2000) and generate "thick" descriptions of practice that can contribute to theory (Geertz 1973; Goodall 2001) this paper offers a more practical contribution in relation to the ethnographic method itself.

Throughout the paper I have drawn on the notion of self-reflexivity in order to denote an explicit focus on myself as an active producer of knowledge, and I would claim that this approach is particularly well suited for shorter ethnographies. Part of the objectives and the approach of longer more traditional ethnographic studies are for the researcher to try to engage away from his or her theoretical preconceptions in order to not risk collapsing practical logic into theoretical logic (Bourdieu and Waquant 1992). Here I engaged instead with my preconceptions and by dwelling on shorter "ethnographic episodes" through a self-reflexive lens I managed to construct a perspective that was new (for me). My insights did not rely as much on the depth of engagement as they did on maintaining a self-reflexive stance. In fact, I argue that it is likely that I could have generated just about the same insights from an even shorter stay than four 
weeks, using this approach (I leave it for another discussion to explore how short).

Ellis and Bochner (2000) argue for the importance of the personal story in research and they state that it "offers lessons for further conversation rather than undebatable facts" (pp. 744); the question to be asked is therefore not how well the personal story represents a certain "reality", but what are the consequences that the story produces (pp. 746). My hope is that the personal story told in this paper can evoke an interest in the use of shorter ethnographic studies to explore the complex practices of building sites. I also hope that it can provide a route towards further discussion and use of ethnographic-based methods in construction. Especially since longer "traditional" ethnographic approaches are considered inaccessible for the majority of researchers, for practical reasons (Pink et al 2012), as well as problematic in regard to the high degree of spatially and temporally distributed activities that characterizes the practices of a building site (Marshall and Bresnen 2012).

This being said, I want to emphasize that shorter self-reflexive ethnographic studies should not (and can not) substitute for longer in-depth studies, but they can provide a valuable complement, both to other ethnographic approaches, and also to other traditional methods such as interviews, focus groups or observations. Dainty (2008) called for the use of multiple methods in construction research. Rather than favouring any particular methods, he highlighted that it is the combinations of several methods that produces new perspectives. 
In regard to this I would like to end by referring to the study of Thiel (2012). He had the privilege to spend 51 weeks participating in the activities of three interlinked building sites. While he saw that participant observation was central to understanding the world of building sites, he also realized that this alone could only produce a partial picture. Instead he argued that the time he spent away from the site doing interviews with the workers provided a vital perspective that complemented the participant observation. He concluded from this that effective ethnography needs the field-worker to both "be there" at the site and "not be there". On the same note, I conclude that being there, on site, if only for a short period, can provide a vital complement to not being there.

\section{ACKNOWLEDGMENT}

I would like to thank Professor Christine Räisänen, who has provided me with insightful comments and fruitful discussions throughout the making of this paper. I would also like to thank the editor and three anonymous reviewers for their very constructive commenting on earlier versions of this paper. All of you helped me significantly in improving this paper, and for that I am very grateful. 


\section{REFERENCES}

Alvesson, M., Hardy, C. and Harley, B. (2008) Reflecting on reflexivity: reflexive textual practices in organization and management theory. Journal of management studies, 45(3), 480-501.

Applebaum, H. A. (1999) Construction workers, USA. Greenwood Publishing Group.

Atkinson, P., Delamont, S. and Housley, W. (2007) Contours of Culture: Complex Ethnography and the Ethnography of Complexity. Lanham: Rowman and Littlefield. 
Bourdieu, P. (1982). Leçon sur la leçon. Paris: Editions de Minuit. Translated as "Lecture o the lecture" in Bourdieu (1990) In other words: Essays towards reflexive sociology. Stanford University Press: Stanford.

Bourdieu, P. (1990) The Scholastic Point of View. Cultural Anthropology 5, 4, 380391.

Bourdieu, P., and Wacquant, L. J. (1992) An invitation to reflexive sociology. University of Chicago Press.

Bresnen, M. (1990) Organising Construction, London: Routledge.

Bresnen, M., Goussevskaia, A., \& Swan, J. (2005) Implementing change in construction project organizations: exploring the interplay between structure and agency. Building Research \& Information, 33(6), 547-560.

Brewer, J (2000) Ethnography. McGraw-Hill International

Christiansen, F. (2012) The Planning Process at a Construction Site. Thesis for Licentiate Degree, Chalmers University of Technology.

Cicmil, S, and Marshall, D (2005) Insights into collaboration at the project level: complexity, social interaction and procurement mechanisms. Building Research and Information, 33(6), 523-535. 
Clifford, J and Marcus, G E (eds.). (1986). Writing culture: The poetics and politics of ethnography. University of California Press.

Cunliffe, A. (2009). Retelling tales of the field: in search of organizational ethnography 20 years on. Organizational Research Methods.

Czarniawska-Joerges, B (2007) Shadowing: and other techniques for doing fieldwork in modern societies. Copenhagen Business School Press DK.

Dainty, A. R., Bagilhole, B. M. and Neale, R. H. (2000) A grounded theory of women's career under-achievement in large UK construction companies. Construction Management \& Economics, 18(2), 239-250

Dainty, A., Green, S., and Bagilhole, B.M., (eds.) (2007) People and Culture in Construction: A Reader, London: Taylor \& Francis.

Dainty, A (2008) Methodological pluralism in construction management research. Advanced research methods in the built environment, 1-13.

Dent, J F (1991) Accounting and organizational cultures: a field study of the emergence of a new organizational reality. Accounting, Organizations and Society, 16(8), 705-732. 
Dingsdag, D P, Biggs, H C and Sheahan, V L (2008) Understanding and defining OH\&S competency for construction site positions: Worker perceptions. Safety Science, 46(4), 619-633.

Ellis, C. and Bochner, A. "Autoethnography, Personal Narrative, Reflexivity: Researcher as Subject" The Handbook of Qualitative Research. (eds.) Norman Denzin and Yvonna Lincoln. Sage, 2000. 733-768.

Fine, G. A. (2003) Towards a peopled ethnography developing theory from group life. Ethnography, 4(1), 41-60.

Geertz, C. (1973) The interpretation of Cultures. Basic Books: NY.

Gherardi, S and Nicolini, D (2002). Learning the trade: a culture of safety in practice. Organization, 9(2), 191-223

Goodall, Bud H.L. (2001). Writing the new ethnography. Walnut Creek, CA: AltaMira.

Gouldner, A. (1970) The Coming Crisis of Western Sociology. Basic Books: New York.

Greed, C. (2000) Women in the construction professions: achieving critical mass. Gender, Work \& Organization, 7(3), 181-196 
Groák, S. (1994) Is construction an industry? Notes towards a greater analytic emphasis on external linkages. Construction management and economics, 12(4), 287-293.

Hayes, N. (2002) Did manual workers want industrial welfare? Canteens, latrines and masculinity on British building sites 1918-1970. Journal of social history, 35(3), 637-658.

Jarzabkowski, P., Bednarek, R. and Cabantous, L. (2014) Conducting global teambased ethnography: Methodological challenges and practical methods. Human Relations, forthcoming.

Katz, J. (2001). From How to Why On Luminous Description and Causal Inference in Ethnography (Part I). Ethnography, 2(4), 443-473.

Knauseder, I (2007) Organisational learning capabilities in swedish construction projects, Thesis for the degree of doctor in philosophy, Chalmers University of Technology. Gothenburg, Sweden.

Löwstedt, M. and Räisänen, C. (2012) 'Playing back-spin balls': narrating organizational change in construction. Construction Management and Economics, $30(9), 795-806$.

Löwstedt, M. and Räisänen, C. (2014). Social identity in construction: enactments and outcomes. Construction Management and Economics, 32(11), 1093-1105. 
Löwstedt, M. (2015) Strategizing in construction: Exploring practices and paradoxes. Thesis for the degree of doctor in philosophy, Chalmers University of Technology. Gothenburg, Sweden.

Marshall, N. and Bresnen, M. (2012) Where is the action? Challenges of ethnographic research in construction. . In: Pink, S., Tutt, D., and Dainty, A. (eds.) Ethnographic Research in the Construction Industry. Routledge

Moore, P. (2012) The physical work of building and renovating houses in Perth, Western Australia. In: Pink, S., Tutt, D., and Dainty, A. (eds.). Ethnographic Research in the Construction Industry. Routledge.

Ness, K (2010) Bringing order to chaos; the management of construction projects. In the " $5^{\text {th }}$ Making Projects Critical Workshop", 20-22 January 2010, Bristol Business School.

Ness, K. (2012) Constructing masculinity in the building trades: 'most jobs in the construction industry can be done by women'. Gender, Work \& Organization, $19(6), 654-676$.

Pink, S., Tutt, D., Dainty, A., \& Gibb, A. (2010). Ethnographic methodologies for construction research: knowing, practice and interventions. Building Research \& Information, 38(6), 647-659. 
Pink, S, Tutt, D and Dainty, A (eds.) (2012) Ethnographic Research in the Construction Industry. Routledge.

Ridley, J and Channing, J (2008) Safety at work. 7ed. Oxford: Butterworth Heinemann

Rosen, M. (1991). Coming to Terms with the Field: Understanding and Doing Organizational Ethnography. Journal of Management Studies, 28(1), 1-24.

Sage, D (2012) The trials, tribulations and translations of an ethnographic researcher in construction. In: Pink, S., Tutt, D., and Dainty, A. (eds.). Ethnographic Research in the Construction Industry. Routledge.

Silverman, D. (1972) "Philosophy and Meaning”, in Filmer, P., Philipson, M., Silverman, D. and Walsh, D. New Directions in Sociological Theory. CollierMacmillan: London.

Strati, A. (2003) Knowing in practice: aesthetic understanding and tacit knowledge, in D. Nicolini, S. Gerhardi and D. Yanow (eds): Knowing in Organizations, Sharpe, Armonk: NY.

Styhre, A, Josephson, P,E, and Knauseder, I (2004) Learning capabilities in organizational networks: case studies of six construction projects. Construction Management and Economics, 22(9), 957, 966. 
Thiel, D. (2012) Ethnography and flux. Identity and epistemology in construction fieldwork. In: Pink, S., Tutt, D., and Dainty, A. (eds.). Ethnographic Research in the Construction Industry. Routledge.

Tutt, D, Pink, S, Dainty, A and Gibb, A (2012) The communication practices of migrant workers in the UK construction industry. In: Pink, S., Tutt, D., and Dainty, A. (eds.) Ethnographic Research in the Construction Industry. Routledge

Van Maanen J. (2011). Ethnography as work: some rules of engagement. Journal of Management Studies, 48(1), 218-234. 